\title{
KARDINAAL JOZEF CARDIJN, STICHTER EN BE- ZIELER VAN DE KAJ EN VKAJ
}

Frea Vancraeynest

\section{Samenvatting}

Kardinaal Jozef Cardijn is een bekende religieuze figuur wiens roots terug te vinden zijn in Halle. Hij was de stichter en bezieler van de KAJ en de VKAJ en verder goed gekend in de gemeenschap door de organisatie van bedevaarten naar zowel Rome als Lourdes. Hij kwam op voor de arbeidersklasse en maakte er zijn levensdoel van om de arbeidersjeugd kansen te geven in het leven, de KAJ was geboren. Deze beweging was bekend over heel Vlaanderen, zo werd ze ook in Gent bekend, en verder verwierf ze ook internationale faam. Om deze unieke Hallenaar en zijn uitzonderlijke werk in de verf te zetten organiseert het Zuidwestbrabants Museum een tentoonstelling waarin het leven en werk van kardinaal Cardijn aan bod komen.

\section{Inleiding}

Kardinaal Cardijn is een bekende figuur over heel Vlaanderen en zelfs over heel België; tijdens de verkiezing van de Grootste Belg een paar jaar geleden eindigde hij op de $23^{\text {ste }}$ plaats, een behoorlijk goed resultaat. Als stichter van de jongerenbeweging KAJ kon hij in heel Vlaanderen op veel bijval rekenen en dit is vandaag de dag niet anders. In heel wat steden en gemeenten is er een straat of plein naar hem vernoemd en ook vanuit de Kerk is de appreciatie voor deze Halse kardinaal duidelijk. Recent werd immers aangekondigd dat een zaligverklaring op handen zou zijn. Indiase priesters startten, met de steun van de internationale Kajottersbeweging, een campagne voor de zalig- en later ook heiligverklaring van kardinaal Cardijn. Deze actie zette de procedure officieel in gang. De beslissing hieromtrent wordt in de loop van 
het komende jaar verwacht maar in afwachting van verder nieuws hierover, kan $u$ zich reeds verdiepen in het leven en werk van kardinaal Jozef Cardijn, door het lezen van dit artikel maar zeker ook door een bezoekje te brengen aan de tentoonstelling in het Zuidwestbrabants Museum te Halle.

\section{Leven van Kardinaal Cardijn ${ }^{1}$}

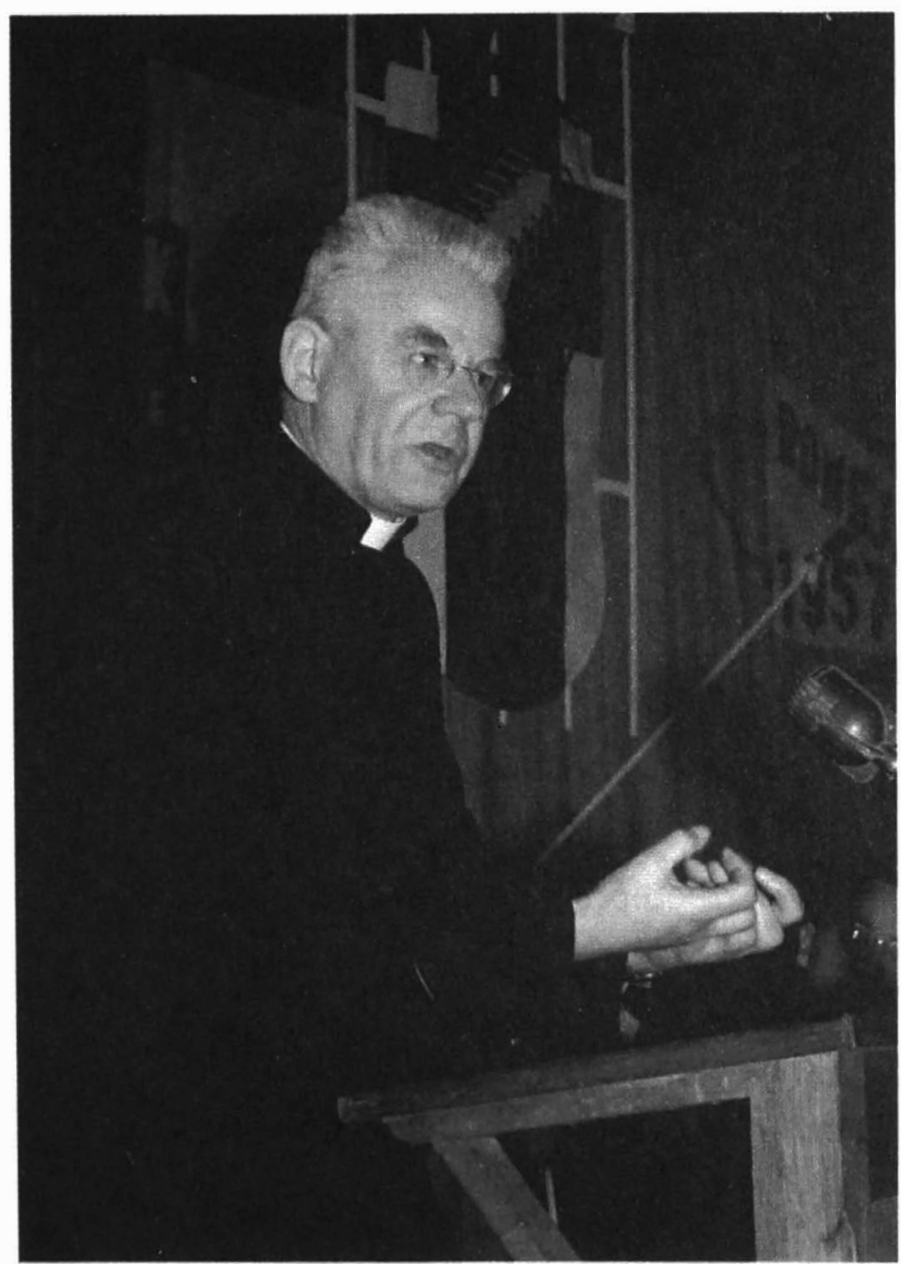

Afb.1. Kardinaal Cardijn

Jozef Cardijn werd geboren op 13 november 1882 in Schaarbeek. Zijn vader Henri was een Hallenaar en zijn moeder Louisa Van Dalen werd geboren in Italië maar groeide op in België. Voor Jozef kreeg het koppel al een dochter en na hem volgden nog twee zonen. Het gezin Cardijn verhuisde in 1884 naar Halle, waar Jozef zijn jeugd doorbracht, zijn opleiding kreeg en waar we ook de kiem van zijn sociaal engagement moeten gaan zoeken.

In 1897 kreeg hij zijn roeping en besloot hij om priester te worden. Hij trok naar het Klein Seminarie in Mechelen en vervolgens naar het Groot Semina- 
rie. Bedoeling was dat hij na zijn priesterwijding sociale en politieke wetenschappen zou gaan studeren in Leuven maar dat ging niet door. Op 12 september 1906 werd hij tot priester gewijd en op 24 september van datzelfde jaar droeg hij in Halle zijn eerste mis op.

Het blijft niet bij preken, Cardijn werd ook leraar, in 1907 in het Klein Seminarie van Neder-Waver.

Zijn interesse voor het lot en de ontwikkeling van de arbeidersjeugd is terug te brengen tot 1912 wanneer Cardijn werkzaam was als onderpastoor in Laken. Dat jaar wordt dan ook gezien als de officieuze start van de KAJ en VKAJ. Hij organiseert tal van evenementen waar verder in dit artikel meer aandacht aan besteed wordt. Cardijn was extreem begaan met zijn werk en deed zijn uiterste best om iedereen een kans te geven. Hij houdt zich dan ook afzijdig van de opkomende poltieke strubbelingen en kiest ervoor om geen banden aan te gaan met het opkomende socialisme, communisme en rexisme. Cardijn wilde er immers zijn voor iedere jongere uit de arbeidersklasse.

Tijdens de wereldoorlogen wordt zijn engagement nog duidelijker. In 1915 toen hij gevangene was van de Duitsers begon hij aan zijn handboek van de 'Katholieke Arbeidersjeugd' (KAJ). Ook tijdens WO II spendeerde hij tijd achter tralies, in juni 1942 werd hij samen met zijn hulpaalmoezenier en de voorzitters van de KAJ en de Waalse tegenhanger JOC gevangen gezet. Hij werd er alleen maar populairder door en na de Tweede Wereldoorlog krijgt zijn KAJ dan ook een internationale dimensie en wist hij miljoenen jongeren wereldwijd warm te maken voor zijn beweging.

Zelf ging het Cardijn eveneens voor de wind. In 1962 vierde hij zijn tachtigste verjaardag in Brussel en werd hij betrokken bij de voorbereiding van het Tweede Vaticaans Concilie. Op 21 augustus 1965 werd Cardijn in Rome door Mgr. Suenens tot bisschop gewijd. Vier dagen later werd hij tot kardinaal gewijd door Paus Paulus VI. Als kardinaal nam hij dan ook deel aan de laatste sessies van het Tweede Vaticaans Concilie waarbij hij, zoals vermeld, reeds betrokken was bij de voorbereidingen.

Cardijn overleed op 24 juli 1967 in Laken. Kardinaal Suenens ging voor in de begrafenisplechtigheid in de basiliek van Koekelberg. Hij werd begraven in de Onze-Lieve-Vrouwekerk van Laken, waar ook de leden van de koninklijke familie hun laatste rustplaats hebben. 


\section{Cardijn en zijn band met Halle- 'Alles wat ik ben en heb komt van Halle'2}

Cardijn is afkomstig uit Halle en die band blijft doorheen de rest van zijn leven een rode draad. De familie Cardijn woonde al sinds de $17^{\mathrm{e}}$ eeuw in Halle en ook Jozef Cardijn is er opgegroeid. Tot zijn veertiende, toen hij naar het seminarie in Mechelen trok, volgde hij les in de Halse school Institut NotreDame-de-Hal. Wanneer hij tot priester werd gewijd verzorgde hij zijn eerste mis in de Sint-Martinusbasiliek in Halle.

De stad Halle vormde en beïnvloedde Cardijn sterk. Niet alleen de Mariacultus die de stad tot bedevaartsoord maakt trof hem, maar eveneens de slechte sociale omstandigheden die gepaard gingen met fabrieksarbeid leerde hij in Halle kennen. Dit bracht hem de sociale voeling met en de zorg om de arbeidersklasse bij die later in zijn werk sterk naar voren kwamen. Zijn vader was kolenhandelaar en de jonge Cardijn werd vaak geconfronteerd met de schrijnende armoede van mensen die geen zak kolen konden betalen. De sociale misstanden waren prominent aanwezig en hij werd tevens sterk beïnvloed door priester Daens die het opnam voor de kleine man en de armoede en sociale wantoestanden wilde aanpakken. Daens bracht in 1895 een bezoek aan Halle, Cardijn was erbij en nam de boodschap van Daens mee in zijn latere leven en werk.

Het is door de nauwe band die Cardijn heeft met Halle dan ook niet verwonderlijk dat de KAJ haar eerste afdelingen in Halle en omstreken oprichtte. in 1925 ontstond al een VKAJ-afdeling in Halle, gevolgd door een KAJ-afdeling. Ook de buurgemeenten Essenbeek, Lembeek, Buizingen en Sint-Rochus lieten niet lang op zich wachten en ook daar werden afdelingen opgericht. En het bleef niet bij lokale initiatieven, delegaties van kajotters en kajotsters uit Halle namen deel aan congressen en bedevaarten, zoals de bedevaart naar Lourdes in 1952 en 1965 en de Romebedevaart in 1957.

Om zijn nagedachtenis levend te houden reikt de vzw Kardinaal Cardijn sinds 1997 tweejaarlijks de Cardijnprijs uit aan een organisatie of initiatief dat het best het gedachtegoed en de erfenis van Cardijn naar voren brengt in de hedendaagse maatschappij.

\section{Stichting van de KAJ en de VKAJ}

Door het zien van de sociale wantoestanden waar de arbeiders mee te maken krijgen tijdens zijn jeugd, groeit bij Cardijn de wens om daar iets aan te doen. Aan het sterfbed van zijn vader beloofde hij om als priester ten dienste te zijn van de arbeiders. Na zijn priesterwijding in 1906 bestudeerde hij de 
situatie van de West-Europese syndicaten. Hij reist in zijn vrije tijd naar Duitsland, Frankrijk en Engeland om de arbeidsomstandigheden van de werkende klasse te gaan bestuderen. In Engeland ontmoet hij verscheidene vakbondsmannen, waaronder Tom Mann en Ben Tillett. Hij blijft op die manier voeling behouden met de internationale arbeidersklasse. Daarnaast ontmoette hij ook de stichter van het scoutisme, Baden Powell. Hij legde Cardijn de idealen en methodes uit die eigen waren aan de scouts en stelde hem voor om de scoutsbeweging te starten in België. Cardijn ging daar echter niet op in. Hoewel hij de scouts wel een goed initiatief vond en het educatieve nut van de beweging wel inzag vond hij dat deze niet voldoende gericht was op de specifieke noden van de arbeidersklasse. Hij dacht dan ook eerder aan het oprichten van een beweging die het arbeidsmidden omvormt en specifiek gericht is op de unieke sociale situatie van de arbeiders ${ }^{3}$.

Tijdens zijn werkzaamheden in Laken in 1912 begon hij jonge arbeiders te organiseren in studiekringen. Hij startte met de voorbereidingen van de oprichting van de Katholieke Arbeidersjeugd (KAJ). Die beweging werd officieel opgericht in 1925, een jaar later gevolgd door de vrouwelijke tegenhanger $\mathrm{VKAJ}^{4}$. De beweging kende ook over de taalgrens succes, in Wallonië ontstond de Jeunesse (JOC) en diens vrouwelijke tegenhanger JOCF.

Vanaf de stichting groeit de KAJ snel uit over het hele land maar ook over de landsgrenzen heen. Er werden ook afdelingen opgericht in Frankrijk, Zwitserland, Canada, Colombia, Nederland, Portugal en Engeland. Op het hoogtepunt van de beweging in de jaren 1950 waren er enkele miljoenen leden wereldwijd te tellen, waarvan enkele tienduizenden in België. De beweging breidde uit tot over 80 verschillende landen. Allen werden georganiseerd in de traditie van de befaamde leuze van Cardijn: 'Zien, Oordelen, Handelen'5.

Een memorabel moment was de bijeenkomst in het Heizelstadion. Op 3 september 1950 kwamen 100000 kajotters naar het stadion afgezakt om samen te komen en te vieren. Er was een gezamenlijke mis's ochtends gevolgd door een picknick en daarna de jubelzitting, waar onder meer een radioboodschap van paus Pius XII te horen was. Cardijn liet zich zelf ook niet onbetuigd en sprak de verzamelde jongeren toe: "Kajotters en Kajotsters, ik reken op u! Wij zweren trouw! Wij zweren trouw aan God en Kerk, land en volk, aan de arbeidende jeugd en de arbeidersstand van Vlaanderen en van de wereld! Wij bouwen een nieuwe wereld! Vooruit! Vooruit!"6. Zijn oratorische kwaliteiten waren enorm en hij slaagde er dan ook in om door zijn typische manier van speechen mensen te inspireren. De samenkomst in Rome in 1957, waar dertigduizend jongeren uit 87 landen aanwezig waren, illustreert de internationale dimensie die de KAJ heeft aangenomen na WO $\mathrm{I}^{7}$.

$\mathrm{Na}$ het overlijden van Cardijn liep het ledenaantal sterk terug maar de beweging bleef wel degelijk bestaan, ook zonder haar bezieler bleef er een plaats voor een beweging in de maatschappij die een stem gaf aan jongeren die het 
moeilijk hadden. Het belangrijkste uitgangspunt is nog steeds het aan boord trekken van jongeren die het moeilijk hebben omwille van sociale, culturele of economische redenen. Een grote diversiteit aan activiteiten, van ontspanningsactiviteiten tot vormende debatten, is eigen aan de beweging.

De stichting van de beweging en de werking ervan is mooi in kaart te brengen door gebruik te maken van de getuigenissen van gewezen Kajotters en Kajotsters. Ook in Halle zijn er zo'n oudleden terug te vinden die graag hun belevenissen met de beweging en Cardijn en de impact ervan op hun leven wilden delen. Stephanie Neetens is er één van, ze was een kajotster in hart en nieren en verblijft nu in een kloostergemeenschap in Halle. Haar levensverhaal krijgt in de tentoonstelling dan ook een prominente plaats ${ }^{8}$.

\section{KAJ en VKAJ, ook in Gent ${ }^{9}$}

Ook de link tussen Cardijn, de KAJ en Gent is onmiskenbaar. Twee albums in 1933 geschonken aan de bisschop van Gent, Honoré Jozef Coppieters, die deel uitmaken van de collectie van het Zuidwestbrabants Museum te Halle, geven een uniek beeld van de toestand en de werking van de KAJ en VKAJ in het bisdom Gent tijdens de periode na de oprichting. De albums werden aan de bisschop gegeven ter gelegenheid van het vijfjarig bestaan van het Diocesaan Sekretariaat. De organisatie wil hiermee de bisschop laten kennismaken met de KAJ en tegelijk ook een overzicht geven van de beweging de afgelopen vijf jaar. Uit de albums blijkt duidelijk dat de organisatie van de beweging reeds van in het prille begin erg gestructureerd was en op een efficiënte manier bestuurd werd. Dit zou deels een verklaring kunnen zijn voor het grote succes van de beweging en vooral ook de sterke start die de beweging doormaakte na de stichting.

Samenvattend geven de albums de toestand van de arbeidersjeugdorganisatie weer na de oprichting. Er wordt in vermeld dat de kaders van de beweging gevormd zijn en de 'publiciteitsperiode' voorbij is. De beweging is klaar om verder uit te breiden, nog degelijker op te voeden en zoals ze het zelf formuleren: "krachtdadiger de arbeidende jeugd in al haar nooden ter zijde te staan.".

Verder stellen ze ook dat de KAJ en de VKAJ in een korte tijdspanne de medewerking verwierven van tienduizenden jonge arbeiders en arbeidsters. Maar ook konden ze het vertrouwen van oudere arbeiders winnen evenals de sympathie van vele anderen. De groei waarop hier geduid wordt is deze in het Gentse gebied, in heel Vlaanderen lagen de cijfers toen veel hoger.

De wens is om de Kajot(s)tersbeweging uitdrukkelijk verder uit te bouwen 
en het verslag aan de bisschop speelt hierin een belangrijke rol: "Moge het verslag bijdragen, om de Kajot(s)tersbeweging nog beter te leeren kennen met haar eigen karakter en methode, moge het helpen om ze overal uit te bouwen."

De KAJ en de VKAJ willen voor de arbeidersjeugd een school van vorming zijn en dit zowel op sociaal als religieus vlak, maar ook een sociale dienst en tevens ook een vertegenwoordigend lichaam dat de stem vormt voor alle jongeren uit de arbeidersklasse.

Deze drie pijlers worden op grondige wijze uitgewerkt en resulteren in een breed gamma aan diverse activiteiten waarvan enkele in het verslag mooi in beeld werden gebracht door enkele unieke en uitzonderlijk goed bewaarde foto's.

Een uitstekend voorbeeld hiervan zijn de verscheidene ontspanningsactiviteiten die door de KAJ georganiseerd werden want ook in de jaren ' 30 deed de $K A J$ al veel meer dan het organiseren van optochten en studiedagen en het samen bidden. De spelletjes die toen gespeeld werden doen sterk denken aan de hedendaagse jeugdbewegingsspelletjes zoals kruiwagen, Dikke Berta, Chinese voetbal en vele andere. Met klinkende namen als 'Gebonden duizendpoot' en 'Kreeftenkoers' lijkt het plezier verzekerd, zoals de bijgevoegde afbeeldingen ook tonen.

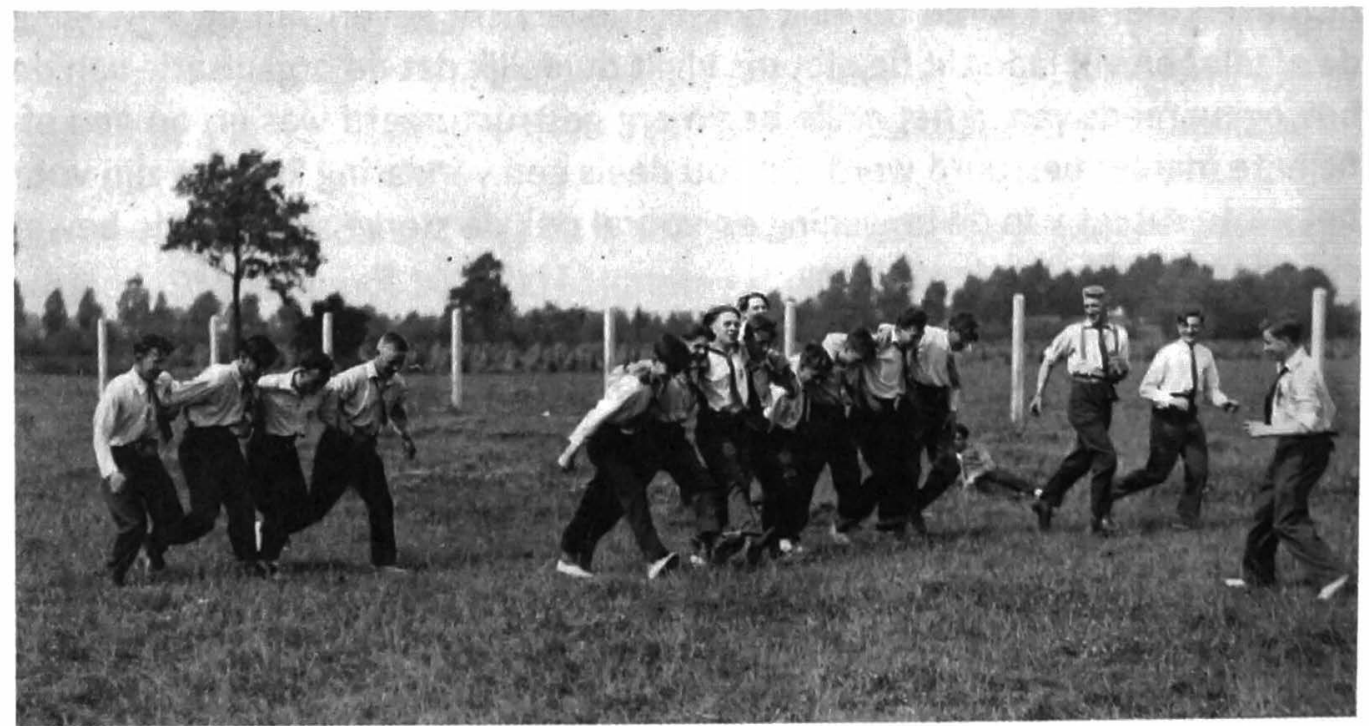

Afb. 2. Gebonden duizend poot 


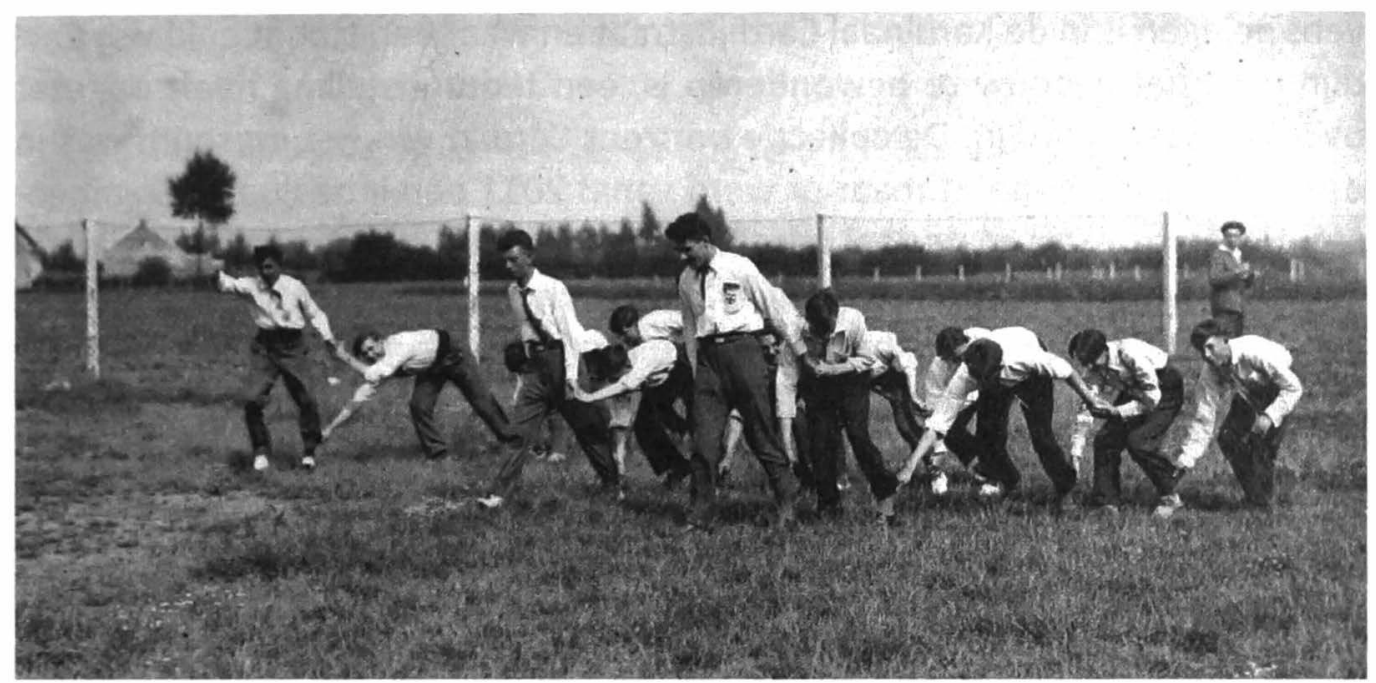

Afb. 3. Kreeftenkoers

Niet alleen de arbeidersjongeren die werk hadden konden rekenen op de KAJ en VKAJ, er werden ook acties op poten gezet om de jonge werklozen een hart onder de riem te steken. Bijgevoegde afbeelding toont hier een voorbeeld van, een boottocht met jonge werklozen langs de haven van Gent.

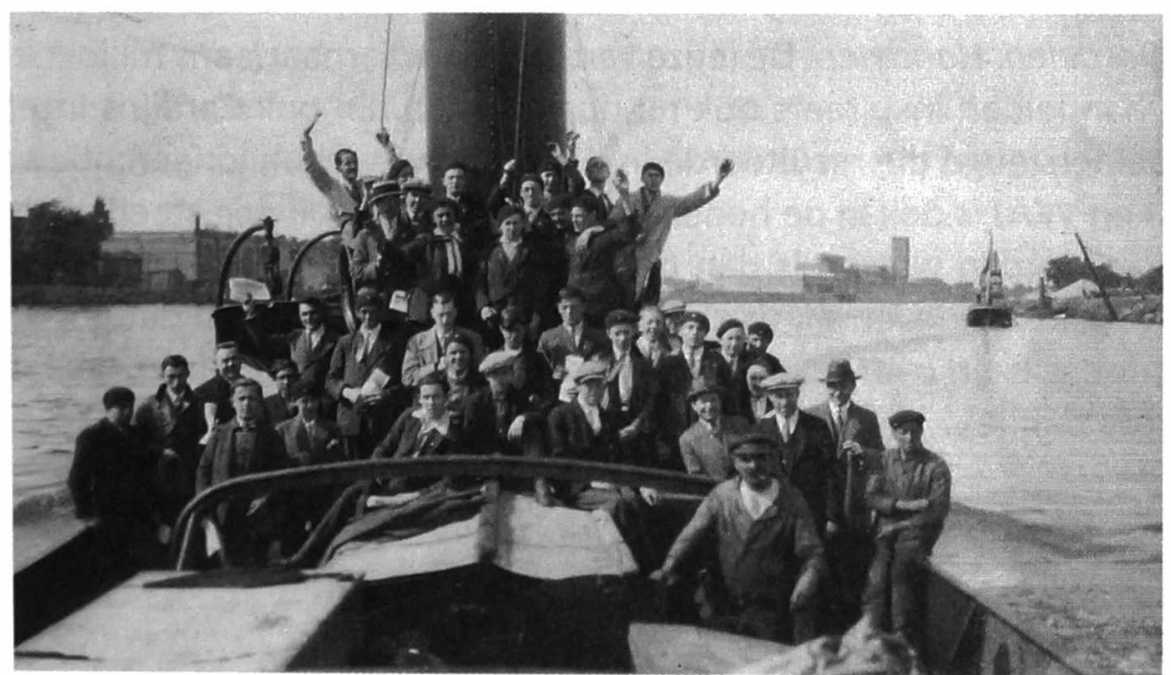

Afb. 4. Boottocht, haven van Gent

Deze en nog vele andere unieke foto's tonen de diversiteit van de beweging.

\section{Expo 'Met Cardijn op Weg'}

De band tussen Halle en Cardijn werd intussen reeds voldoende duidelijk en het is dan ook niet verwonderlijk dat het Zuidwestbrabants Museum, dat te- 
vens gelegen is in de Kardinaal Cardijnstraat en waar een standbeeld van Cardijn voor het gebouw te bewonderen is, een tentoonstelling heeft opgezet over kardinaal Cardijn. De collectie omtrent Cardijn van het museum was in eerste instantie beperkt maar er werd vanaf 2011 een inhaalbeweging ingezet. Heel wat extra materiaal bereikte het museum, waaronder de collectie van de Halse vzw Kardinaal Cardijn. Het resultaat is een tentoonstelling die een thematische invulling heeft gekregen: er wordt gefocust op de congressen en internationale bedevaarten van de KAJ tijdens het leven van Cardijn.

De tentoonstelling is nog te bezoeken tot en met 31 oktober. Ook de catalogus die bij de expo 'Met Cardijn op weg' hoort en rijkelijk geillustreerd is met niet eerder gebruikt beeldmateriaal, is verkrijgbaar via het Museum. Wie meer informatie wil over de expo, Cardijn of de KAJ kan steeds een beroep doen op het Zuidwestbrabants Museum te Halle. Voor groepen is de tentoonstelling elke dag te bezoeken (na afspraak); individuele bezoekers zijn welkom op zondag van 14 tot 17 uur. Meer info: www.streekmuseum-halle. be; museum@halle.be; 023659765.

\section{Besluit}

2 Zien. Oordelen. Handelen. De leuze van Cardijn waarnaar eens miljoenen jongeren handelden inspireert ook nu nog mensen. En ook Cardijns inzet voor de arbeidersjeugd die resulteerde in de uitbouw van een jongerenbeweging, de KAJ en VKAJ is ook in de hedendaagse maatschappij nog steeds zichtbaar. Kardinaal Cardijn was en is dan ook een populair man, die nooit zijn Halse roots vergat. Zijn leven en werk vertellen een uniek verhaal dat goed gedocumenteerd is en over heel Vlaanderen en ver daarbuiten herkenbaar is bij het grote publiek. 


\section{Noten}

1. P. François, 'Met Cardijn op weg', catalogus van de tentoonstelling in het Zuidwestbrabants Museum Halle, 12 mei 2012 tot 31 oktober 2013', Halle, Zuidwestbrabants Museum, 2013, p. 9 e.v.

2. P. François, 'Met Cardijn op weg', p. 20-21.

3. Zie voor deze paragraaf: http://www.catholicauthors.com/cardijn.html, laatst geraadpleegd op 29 augustus 2013.

4. P. François, 'Met Cardijn op weg', p. 11-12.

5. P. François, 'Met Cardijn op weg', p. 13.

6. P. François, 'Met Cardijn op weg', p. 13-14.

7. P. François, 'Met Cardijn op weg', p. 18.

8. P. François, 'Met Cardijn op weg', catalogus van de tentoonstelling in het Zuidwestbrabants Museum Halle, 12 mei 2012 tot 31 oktober 2013', Halle, Zuidwestbrabants Museum, 2013, p. 23 e.v.

9. Alle informatie binnen deze titel is afkomstig uit twee albums die geschonken werden aan de bisschop van Gent en nu deel uitmaken van de collectie van het Zuidwestbrabants Museum in Halle. 


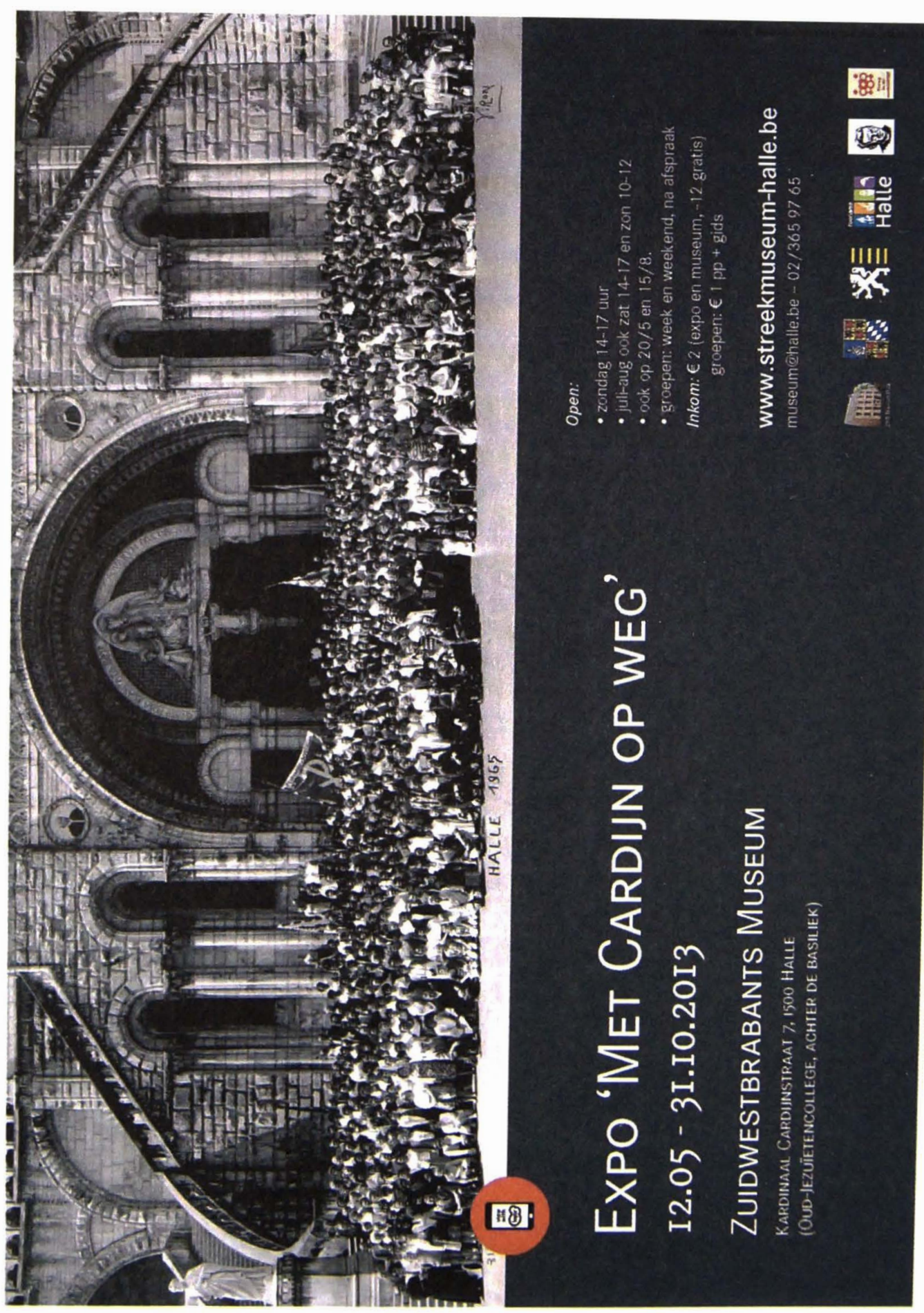

Afb. 5. Poster van de expo 'Met Cardijn op weg' 12.05 - 31.10.2013 Zuidwestbrabants Museum, Halle www.streekmuseum-halle.be 